\title{
The Effectiveness of Natural Science Learning Based on Contextual Teaching and Learning in Improving The Critical Thinking Skills of Elementary School Students
}

\author{
N. Hariyati, Tarma \\ Universitas Negeri Surabaya \\ Surabaya, Indonesia \\ nunukhariyati@unesa.ac.id
}

\begin{abstract}
This study aims to measure the contribution of information literacy, emotional regulation and self-directed learning on the behavior of procrastination. Research conducted in December 2016 at the Faculty of Engineering, the State University of Jakarta with 341 respondents from various departments. The method used was quantitative descriptive survey approach. The research found that: (1) the correlation coefficient between the information literacy with procrastination behavior is $\mathbf{- 0 . 1 9 2}$ (negative correlation); (2) the correlation coefficient between emotional regulation with procrastination behavior is $\mathbf{- 0 . 1 9 2}$ (negative correlation); and (3) the correlation coefficient between self-directed learning with procrastination behavior is $\mathbf{- 0 . 2 7 9}$ (negative correlation). The correlation between the information literacy with self-directed learning is at 0.645 and the correlation between emotional regulation with self-directed learning is at $\mathbf{0 . 5 5 1}$. Based on these findings, the intervention variable information literacy, emotional regulation and selfdirected learning can reduce procrastination behavior problems of students of vocational teacher education.
\end{abstract}

\section{Keywords-Contextual Learning, Improve skills}

\section{INTRODUCTION}

Teachers must have the ability to manage the job well. Working as a teacher, one has many tasks to do such as planning lessons, carrying out teaching, doing learning evaluations, doing classroom-based research, coaching students, and developing schools. To be able to manage the teacher's responsibility well, the teacher education student must have good ability on managing the task, the time, and the ability to set priority and do the job well.

There are many behavioral problems detected in teacher education students. One of them is the habit of doing the task at the end of time. This negative habit resulted in students' poor quality papers and project. The habit of delaying such work in behavioral science is known as procrastination. This study measures the procrastination behavior in students of the vocational teacher education program. In addition, this study also revealed the determinants of procrastination behavior in students (Toker, B., \& Avci, R. 2015).
Student inability to manage emotions can lead to student procrastination behavior. Students need to have the ability to manage their emotions to succeed academically. Emotion regulation is how individuals change their emotional experience to make it more manageable (Leone, Gillespie, Orr, and Harrington, 2015).

To be successful academically, students must have the ability to learn independently. Independent learning disabilities can cause students difficulties in learning and cause students to procrastinate. The ability to learn independently is known as self-directed learning (Andrade \& Bunker. 2009). Self-directed training includes the learner initiating the learning, making the decisions about what training and development experiences will occur, and how. The learner selects and carries out their own learning goals, objectives, methods and means to verify that the goals were met (Chien, and Tsai, 2015). This study aims to measure: (1) the influence of information literacy on procrastination behavior; (2) the influence of self-directed learning on procrastination behavior; And (3) the effect of emotional regulation on procrastination behavior.

\section{LITERATURE REVIEW}

\section{A. Procrastination}

Procrastination defined as unnecessarily putting off, or delaying activities that one ultimately intends to complete, especially when is done to the point of creating emotional discomfort (Lay, 1993; Solomon \& Rothblum, 1984). Procrastination is a multi-dimensional construct that appears to have behavioral, cognitive and affective components. It has been extensively researched resulting in many theories as to its cause, with evidence linking it to negative personality traits, self-regulation failure, temporal discounting and individual differences (Ferrari, 1992; Steel, 2007) as well as impulse control and avoidant coping styles (Sirois, Melia-Gordon, \&Pychyl, 2003). 


\section{B. Emotional Regulation}

There are numerous definitions of emotion regulation in the literature. These definitions differ in several ways, including the extent to which they (a) distinguish between emotion generation and regulation, (b) emphasize the explicit versus implicit nature of emotion regulation, and (c) focus on inter- personal versus intrapersonal processes (Laveder, J. M. et al., 2015). The multidimensional model conceptualizes emotion regulation as adaptive responses to emotional distress and is characterized by four dimensions: (a) flexible use of adaptive strategies to modulate (vs. eliminate) the intensity and/or temporal features of an emotional response; (b) ability to resist impulsive behaviors and engage in goal-directed behaviors in the context of emotional distress; (c) emotional awareness, clarity, and acceptance; and (d) willingness to experience emotional distress in the context of pursuing meaningful activities (Laveder, J. M. et al., 2015).

\section{Self-Directed Learning (SDL)}

SDL is a continuous engagement in acquiring, applying and creating knowledge and skills in the context of an individual learner's unique problems (Stewart, 2007). SDL capabilities are critical in the ever-changing knowledge economy where there are constant changes. Instilling a lifelong learning perspective implies that schools and universities need to prepare learners to engage in SDL processes (Barrows H. S 1986).

\section{Information Literacy}

The concept of information literacy according to Reitz also includes the ability necessary to evaluate the content of information critically and use it effectively as an understanding of technological devices as the basis for the delivery of information, including the social, political and cultural fields and their impacts (Castells, M. 2011). Meanwhile, Bruce said that information literacy is an ability to access, evaluate, organize and use information in the learning process, problem solving, making formal and informal decisions in the context of learning, work, home and in education (Koltay, T. 2011).

With regard to the concept of information literacy, many standards are advanced by experts (Brand-Gruwel, S., Wopereis, I., \& Vermetten, Y. 2005). Campbell describes several standards of information literacy capabilities such as: (1) recognize information needs; (2) locate and evaluate the quality of information; (3) store and retrieve information; (4) make effective and ethical use of information; and (5) apply information to create and communicate knowledge (Catts and Jesus, 2008).

\section{METHODS}

This research uses a qualitative method by using survey technique. The population of this study is 3,320 students of vocational teacher education program, Faculty of Engineering, State University of Jakarta. The sample of this research is 341 students.
Data was collected using questionnaires. Emotional regulation variable was measured using ERQ (Emotional Regulation Questionnaire) that has been developed by Gross and John. Information literacy was measured using instruments developed by Campbell. Procrastination behavior was measured using instruments developed by Piers Steel. Selfdirected learning was measured using SDLRS (Self-Directed Learning Readiness Scale) developed by Guglierminos.

\section{RESULT AND DISCUSSION}

\section{A. Procrastination Behavior}

The measurement of procrastination behavior was through questionnaire with 20 statement items. Based on the results of data processing the maximum score is known to be 70 , the minimum score is 27 . The average score is 56.83. Student procrastination behavior is at the level of $56.83 \%$ of ideal. On a scale of $1-5$, the ability of new information literacy reaches the point of 2.84. It shows that the ability of self-directed learning is a high category.

Based on the per-item analysis it is known that the lowest item score is delaying to do the work. It means that the student relatively does not delay the task. Meanwhile, the highest item is shown on an item about a long time to compose a paper. This suggests that the ability of the students in writing papers and arrange a time to prepare papers are still not optimal.

To reduce procrastination behavior, Edith Cowan University suggests 20 strategies. That strategies include Worst-first approach, remember-forgetting technique, bits and pieces approach, break it down, five-minute plan, positives and negatives, reward yourself, ask for help, pick your times, pick your times, establish priorities, manage time, change environment, minimize potential distractions, visible reminders, self-monitoring, talk self into it, set some goals, know thinking, and be persistent but patient. Other tips suggest by Center for Clinical Intervention to stop procrastination behavior, namely: worst-first, using momentum, just 5minutes, set time limits, prime time, prime place, rememberthen-do, reminders, visualize, focus, and plan rewards. To reduce student procrastination behavior, the campus needs to arrange training to train the skills to stop procrastination. 


\section{B. Information Literacy}

Information literacy was measured using a questionnaire with 44 items statement. Based on the results of data processing it was known that the maximum score is 220 and the minimum score is 87 . The average score is 146.64 . The ability of student information literacy is at level $66,67 \%$ from ideal. On a scale of 1-5, the literacy capability of new information reached 3.33. It shows that the ability of information literacy is still low.

Based on the per-item analysis it is known that the lowest item score is the ability to write articles and publish them in print. This shows that students' writing ability still needs improvement. Meanwhile, the highest score item is the ability to use search engines when not knowing the reference website needed.

To increase information literacy, many efforts needed. Some of them are collaborative efforts to improve information literacy and an intentional student learning outcome. They were successful in enhancing the quality of research that students conducted. Utilizing three different instances: library assessment, the professor and librarians, were able to see tangible results from the extra information literacy instruction.

\section{Self-Directed Learning}

Self-directed learning was measured using a questionnaire with 40 statement items. Based on the results of data processing it was known that the maximum score of 200, the minimum score is 101 . The average score is 151.39 . The student's self-directed ability is at $75.70 \%$ of the ideal. On a scale of $1-5$, the literacy capacity of the new information reached the level of 3.78 . It shows that the ability of selfdirected learning is still in moderate category.

Based on the results of the analysis per-item questionnaire about self-directed learning it needs to be highlighted that the item with the highest score is the feelings need to learn. Meanwhile, the scores of the lowest self-directed learning item is on the item about the specific timing for learning.

To improve self-directed learning, Center For Teaching Excellence The University of Waterloo suggests the following stages. First, be ready to learn. Various skills and attitudes towards learning are required for successful independent study This step requires time for analyzing student current situation, study habits, family situation, and support network both at school and at home - and as they continue in the program, progress in degree program and past units taken that will prove useful. Signs of readiness for self-directed learning include being: autonomous, organized, self-disciplined, able to communicate effectively, and able to accept constructive feedback and engage in self-evaluation and self $\neg$-reflection. Second, setting learning goal.

\section{Determinant Factors of Procrastination Behavior}

Based on correlation test results among determinant variables some points were emerged as follows: the correlation coefficient between the information literacy with procrastination behavior is -0.192 (negative correlation). Variable information literacy contributes to procrastination behavior $4 \%$. It means that behavior of high procrastination behavior caused by weakness of literacy ability, so that student find difficulties in finding, processing, compiling and writing information into the task. The correlation coefficient between emotional regulation with procrastination behavior is -0.192 (negative correlation). Variable emotional regulation contributes to procrastination behavior by $4 \%$. It means that procrastination behavior is caused by weak emotional regulatory capabilities. To reduce the behavior of procrastination, the campus needs to intervene the program by increasing the ability of students' emotional regulation.

The correlation coefficient between self-directed learning with procrastination behavior is -0.279 (negative correlation). Variable self-directed learning contributes to procrastination behavior by $8 \%$. It means that the behavior of procrastination occurs because of the ability of students' self-directed learning which is still need to be improved. If students have high selfdirected learning ability, it will reduce procrastination behavior.

The correlation between the information literacy with selfdirected learning is at 0.645 and the correlation between emotional regulation with self-directed learning is at 0.551 . Based on these findings, the intervention variable information literacy, emotional regulation and self-directed learning can reduce procrastination behavior problems in vocational teacher education students. Research result is shown in Figure 1 bellow.

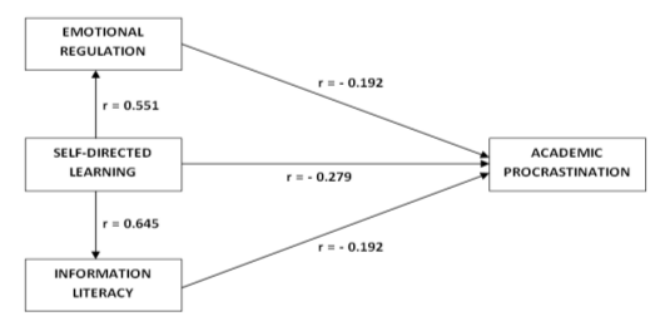

FIGURE 1. RESEARCH RESULT

\section{CONCLUSION}

Based on the findings and discussion of the results it can be concluded as follows: the literacy ability of information is negatively correlated with procrastination behavior. The higher the literacy capacity of information will lead to lower procrastination behavior. The emotional regulation ability is negatively correlated with procrastination behavior. The higher the emotional regulation ability of the students will lead to lower procrastination behavior (Wolters, C. A. 2003). The ability of self-directed learning is negatively correlated with procrastination behavior. The higher the ability of self- 
directed learning in the students will lead to lower procrastination behavior. To reduce the behavior of procrastination can be done by intervention on increasing information literacy, emotional regulation, and self-directed learning.

\section{REFERENCES}

[1] Day,V., Mensink, D., \& O'Sullivan,M. (2000). Patterns of Academic Procrastination. Journal of College Reading and Learning, 30, 120-134.

[2] Ferrari, J.R. (1992). Psychometric Validation Of Two Procrastination Inventories for Adults: Arousal and Avoidance Measures. Journal of Psychopathology and Behavioral Assessment. 14(2), 97-110.

[3] Ferrari,J.R., \& Tice, D.M. (2000). Procrastination as a Self-Handicap for Men and Women: A Task- Avoidance Strategy in a Laboratory Setting. Journal of Research in Personality, 34,73-83.

[4] Harriott, J., \&Ferrari, J. R. (1996). Prevalence of Procrastination Among Samples of Adults. Psychological Reports, 78, 611-616.

[5] Hoover, E. (2005). Tomorrow I LoveYa!. Chronicle of Higher Education, 52 (16), A30-A32.

[6] In J.R., Ferrari, J.L., Johnson, and W.G. McCown (Eds.). (2010) Procrastination and Task Avoidance: Theory, Research, and Treatment. New York: Plenum Press.
[7] Laveder, J. M. et al. (2015). Development and Validation of a StateBased Measure of Emotion Dysregulation: The State Difficulties in Emotion Regulation Scale (S-DERS). Faculty Publications, Department of Psychology. Paper 679.

[8] Solomon, L. J., \& Rothblum, E. D. (1984). Academic Procrastination: Frequency and Cognitive-Behavioral Correlates. Journal of Counseling Psychology, 31, 503-509.

[9] Barrows, H. S. (1986). A taxonomy of problem-based learning methods. Medical education, 20(6), 481-486.

[10] Koltay, T. (2011). The media and the literacies: Media literacy, information literacy, digital literacy. Media, Culture \& Society, 33(2), 211-221.

[11] Brand-Gruwel, S., Wopereis, I., \& Vermetten, Y. (2005). Information problem solving by experts and novices: Analysis of a complex cognitive skill. Computers in Human Behavior, 21(3), 487-508.

[12] Toker, B., \& Avci, R. (2015). Effect of Cognitive-Behavioral-TheoryBased Skill Training on Academic Procrastination Behaviors of University Students. Educational Sciences: Theory and Practice, 15(5), 1157-1168.

[13] Wolters, C. A. (2003). Understanding procrastination from a selfregulated learning perspective. Journal of Educational Psychology, 95(1), 179.

[14] Castells, M. (2011). The rise of the network society: The information age: Economy, society, and culture (Vol. 1). John Wiley \& Sons

[15] Andrade, M. S., \& Bunker, E. L. (2009). A model for self-regulated distance language learning. Distance Education, 30(1), 47-61. 